\title{
Article \\ Synthesis and Spectral Characteristics Investigation of the 2D-2D vdWs Heterostructure Materials
}

\author{
Tao Han (D), Hongxia Liu *(D), Shulong Wang *(D), Shupeng Chen, Kun Yang and Zhandong Li \\ Key Laboratory for Wide-Band Gap Semiconductor Materials and Devices of Education, \\ The School of Microelectronics, Xidian University, Xi'an 710071, China; 15639119745@163.com (T.H.); \\ spchen@xidian.edu.cn (S.C.); kuny2019@163.com (K.Y.); dong2890530@163.com (Z.L.) \\ * Correspondence: hxliu@mail.xidian.edu.cn (H.L.); slwang@xidian.edu.cn (S.W.)
}

Citation: Han, T.; Liu, H.; Wang, S.; Chen, S.; Yang, K.; Li, Z. Synthesis and Spectral Characteristics Investigation of the 2D-2D vdWs Heterostructure Materials. Int. J. Mol. Sci. 2021, 22, 1246. https://doi.org/ $10.3390 /$ ijms 22031246

Received: 24 December 2020

Accepted: 26 January 2021

Published: 27 January 2021

Publisher's Note: MDPI stays neutral with regard to jurisdictional claims in published maps and institutional affiliations.

Copyright: (C) 2021 by the authors Licensee MDPI, Basel, Switzerland This article is an open access article distributed under the terms and conditions of the Creative Commons Attribution (CC BY) license (https:// creativecommons.org/licenses/by/ $4.0 /)$

\begin{abstract}
Due to the attractive optical and electrical properties, van der Waals (vdWs) heterostructures constructed from the different two-dimensional materials have received widespread attention. Here, $\mathrm{MoS}_{2} / \mathrm{h}-\mathrm{BN}, \mathrm{MoS}_{2} /$ graphene, $\mathrm{WS}_{2} / \mathrm{h}-\mathrm{BN}$, and $\mathrm{WS}_{2} /$ graphene vdWs heterostructures are successfully prepared by the CVD and wet transfer methods. The distribution, Raman and photoluminescence (PL) spectra of the above prepared heterostructure samples can be respectively observed and tested by optical microscopy and Raman spectrometry, which can be used to study their growth mechanisms and optical properties. Meanwhile, the uniformity and composition distribution of heterostructure films can also be analyzed by the Raman and PL spectra. The internal mechanism of Raman and PL spectral changes can be explained by comparing and analyzing the PL and Raman spectra of the junction and non-junction regions between 2D-2D vdWs heterostructure materials, and the effect of laser power on the optical properties of heterostructure materials can also be analyzed. These heterostructure materials exhibit novel and unique optical characteristics at the stacking or junction, which can provide a reliable experimental basis for the preparation of suitable TMDs heterostructure materials with excellent performance.
\end{abstract}

Keywords: vdWs heterostructure; Raman spectrum; PL spectrum

\section{Introduction}

Nanoscale PN heterostructure research is particularly important as the device size decreases. However, due to the dangling bonds and lattice mismatch, it is difficult for the traditional materials to achieve atomically flat heterostructure interfaces, which limits the development of nanoscale PN heterostructures [1-3]. Two-dimensional (2D) layered materials have attracted widespread attention due to their novel and unique electronic and optical properties $[4,5]$. The discovery of graphene and transition metal dichalcogenide (TMD) materials has brought new opportunities for the development of PN junction components [6]. The layers of 2D materials can be connected by weak van der Waals (vdWs) interactions and there are no surface dangling bonds [7-9]. This is conducive to the formation of high-quality vdWs heterostructures, which cannot be limited by the lattice matching conditions [10]. The surface of 2D layered materials are without dangling bonds, which can be combined by vdWs forces. Nanoscale vdWs heterostructures can be prepared by simply stacking 2D materials, which can not only allow studies on some new physical mechanisms, but also realize integrated electronic and optoelectronic devices based on various functions of atomic-level flat heterostructures [11-13].

Graphene has the novel physical properties, strong mechanical stability, high mobility and the unique electronic properties of zero-band gap Dirac semimetals, which can make it a basic component of vdWs heterostructures $[14,15]$. The atoms of hexagonal boron nitride (h-BN) can be bound by strong ionic bonds and there are no dangling bonds on the surface, so its physical and chemical properties are relatively stable. Based on the abovedescribed unique properties, h-BN is widely used as a substrate material $[16,17]$. 
Layered TMD materials have become the focus of basic research and technical applications, which is due to their unique crystal structures, a wide range of chemical compositions and their excellent physical and chemical properties [18]. Specific heterostructures can be manufactured by stacking the $2 \mathrm{D}$ layered materials with different properties. At this time, the mechanical stability of 2D material can be maintained due to the strong covalent bonding of heterostructure layers and weaker vdWs interactions between the layers can connect different layer materials [19-21]. vdWs heterostructures can provide additional degrees of controllable freedom, such as the number of layers and the corners between floors, etc [22]. The energy band structure and electron transport characteristics of systems can be changed by adjusting these degrees of freedom. There are no dangling bonds on the surface of layered materials, so they can be used to design and form various high-quality vdWs heterostructures and novel electronic devices with special functions [23]. Due to the existence of weaker vdWs forces between layers, 2D materials can be easily thinned by a mechanical stripping method. The chemical vapor deposition (CVD) method still has great challenges in the control of film size and number of layers, large-scale heterostructure preparation and free construction, which have become important factors restricting the scale and industrial application of 2D TMDs heterostructure materials [24]. Besides, the in depth study of the excitonic emission, energy band regulation and interlayer coupling basic characteristics of 2D heterostructure materials, which are the basis for the realization of various device applications, has very important scientific significance and practical value.

To solve the difficulties and challenges in the application of 2D-2D vdWs heterostructure materials, vdWs heterostructure materials were prepared by the direct CVD and wet transfer methods in this paper. The resulting vdWs heterostructures have ultra-clean and atomically clear interfaces, and novel physical properties appear when 2D materials with different properties are stacked together, which can provide a multifunctional research platform for the study of interface-related characteristics [25]. In addition, the components material selection, layer thickness and the twist angle between layers can greatly enrich the types of vdWs heterostructure materials [26]. Their optical and electronic properties can be tuned by adjusting their multiple degrees of freedom, which has shown great application prospects in the fields of optoelectronic devices, energy and catalysis.

\section{Results and Discussion}

\subsection{Optical Micrographs of 2D-2D vdWs Heterostructure Materials}

The morphology of 2D-2D vdWs heterostructure materials can be observed by optical microscopy. In Figure 1a, a continuous $\mathrm{MoS}_{2}$ thin film is formed on a h-BN/SiO $2 / \mathrm{Si}$ substrate by the Frank Van der Merwe mechanism. This is because the surface of h$\mathrm{BN}$ is clean and smooth, which is beneficial to the sulfidation and diffusion of $\mathrm{MoS}_{2}$ molecules. The large-sized triangular $\mathrm{MoS}_{2}$ materials are evenly distributed on graphene when the CVD growth of $\mathrm{MoS}_{2}$ material is completed, and the $\mathrm{MoS}_{2}$ and graphene materials on $\mathrm{SiO}_{2} / \mathrm{Si}$ substrate can be well distinguished with the help of contrast as shown in Figure $1 \mathrm{~b}$. Figure $1 \mathrm{c}$ is the optical microscopy image of $\mathrm{WS}_{2} / \mathrm{h}-\mathrm{BN}$ heterostructure at different positions on the $\mathrm{SiO}_{2} / \mathrm{Si}$ substrate. The average size of the $\mathrm{WS}_{2}$ material on $\mathrm{h}-\mathrm{BN} / \mathrm{SiO}_{2} / \mathrm{Si}$ substrate is about $30 \mu \mathrm{m}$, the thickness is uniform and the surface is smooth. The edge of the h-BN sheet has many dangling bonds, which can provide nucleation sites for the growth of $\mathrm{WS}_{2}$ material. Figure $1 \mathrm{~d}$ shows a typical optical microscope image of a $\mathrm{WS}_{2}$ /graphene heterostructure, where the triangle-shaped $\mathrm{WS}_{2}$ sheet has an average size of $60 \mu \mathrm{m}$. In addition, there is also a stack of small triangles on the large triangle of $\mathrm{WS}_{2}$ material, which indicates the existence of multilayer triangular $\mathrm{WS}_{2}$ sheets. 

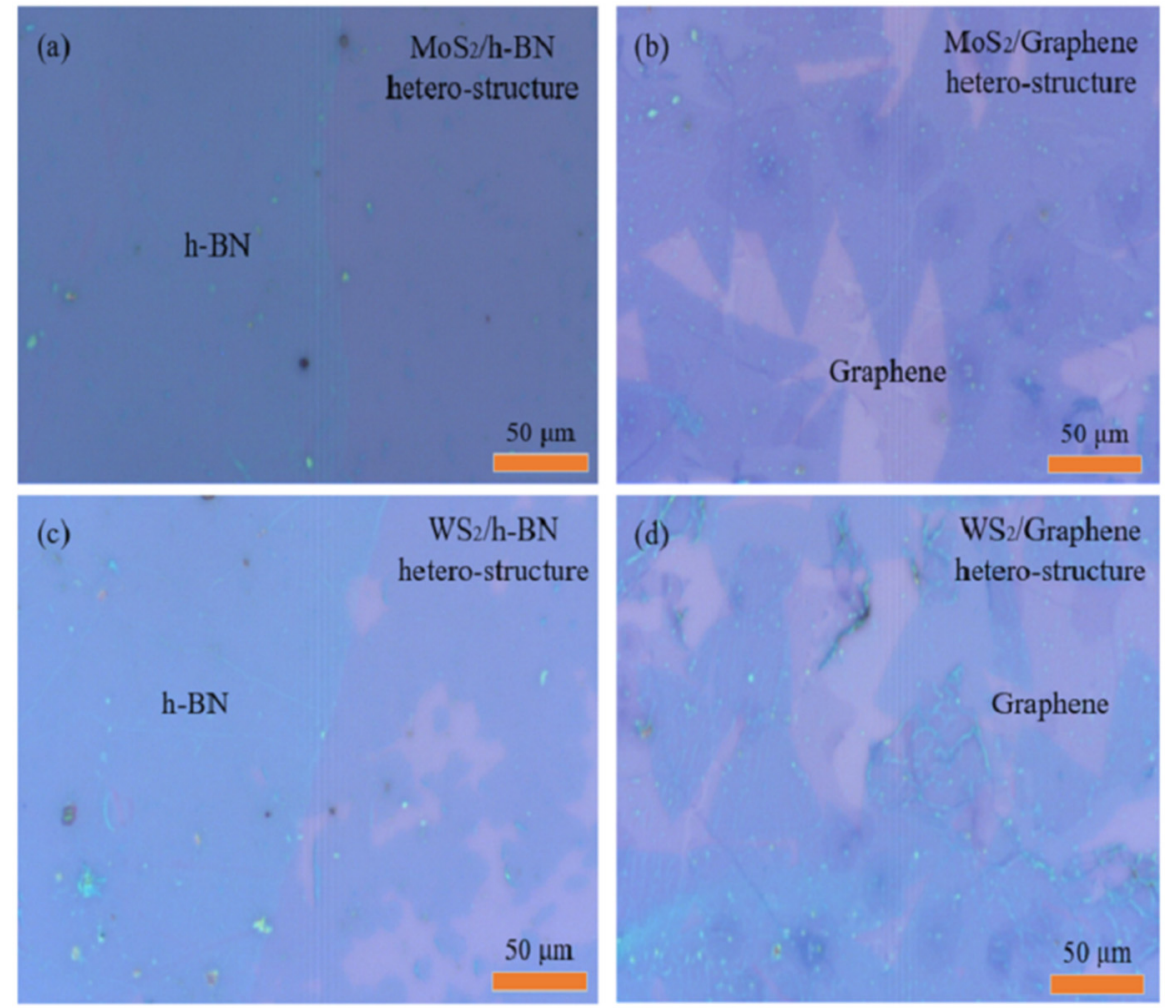

Figure 1. Optical micrograph of (a) $\mathrm{MoS}_{2} / \mathrm{h}-\mathrm{BN}$, (b) $\mathrm{MoS}_{2} /$ graphene, (c) $\mathrm{WS}_{2} / \mathrm{h}-\mathrm{BN}$, (d) $\mathrm{WS}_{2} /$ graphene heterostructures at different positions on $\mathrm{SiO}_{2} / \mathrm{Si}$ substrate.

\subsection{The Test Experiment Results of 2D Materials}

In Figure 2a, graphene material has $\mathrm{G}$ and 2D Raman characteristic peaks; the peak position of the $G$ and $2 D$ peaks are respectively located at $1585.9 \mathrm{~cm}^{-1}$ and $2631.3 \mathrm{~cm}^{-1}$, and the intensity of the 2D peak is stronger than that of the $G$ peak, so the monolayer graphene material has good quality [27]. Figure $2 \mathrm{~b}$ shows the power Raman spectrum of graphene material, where the peak intensity of the $G$ and 2D peaks increases with the increase of laser power, and the peak position does not change. Meanwhile, the ratio of $\mathrm{I}_{2 \mathrm{D}} / \mathrm{I}_{\mathrm{G}}$ decreases, which is due to the interaction change between graphene material and the underlying $\mathrm{SiO}_{2} / \mathrm{Si}$ substrate.
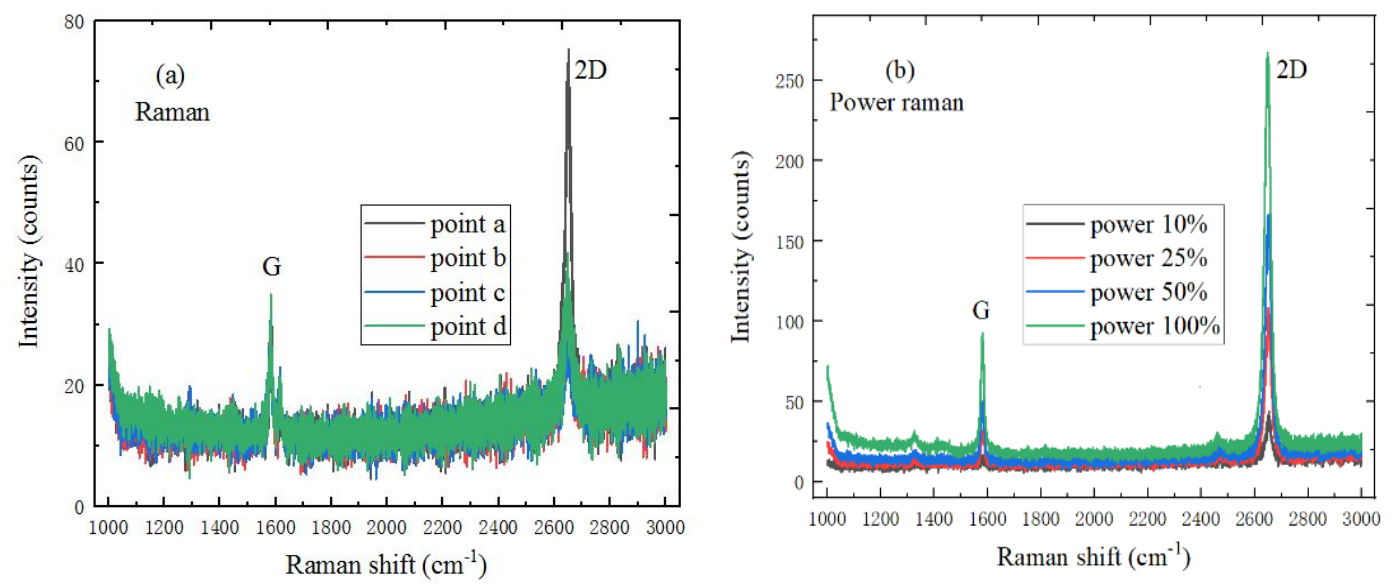

Figure 2. Spectral characteristics of graphene (a) Raman spectrum (10 mW, $633 \mathrm{~nm})$, (b) Power Raman spectrum $(2 \mathrm{~mW}, 5 \mathrm{~mW}, 10 \mathrm{~mW}, 20 \mathrm{~mW}$ and $633 \mathrm{~nm})$.

Figure 3a shows the Raman spectrum of $\mathrm{MoS}_{2}$ at different positions, the lattice vibration of $\mathrm{MoS}_{2}$ has the $\mathrm{E}_{2 \mathrm{~g}}^{1}$ and $\mathrm{A}_{1 \mathrm{~g}}$ Raman active characteristic phonon peaks, where 
the $\mathrm{E}_{2 \mathrm{~g}}^{1}$ and $\mathrm{A}_{1 \mathrm{~g}}$ characteristic peaks were respectively derived from intra-layer lattice and inter-layer lattice vibrations. The two lattice vibration modes change accordingly with the layer number of $\mathrm{MoS}_{2}$ material decreases, and the $\mathrm{E}^{1}{ }_{2 \mathrm{~g}}$ and $\mathrm{A}_{1 \mathrm{~g}}$ characteristic peaks are respectively red-shifted and blue-shifted, so the number of $\mathrm{MoS}_{2}$ material layers can be determined by the peak position difference. In the Raman spectrum of $\mathrm{MoS}_{2}$, the characteristic peaks of $\mathrm{E}_{2 \mathrm{~g}}^{1}$ mode and $\mathrm{A}_{1 \mathrm{~g}}$ mode are respectively located at $382.1 \mathrm{~cm}^{-1}$ and $401.4 \mathrm{~cm}^{-1}$, and the characteristic peak position difference is $19.3 \mathrm{~cm}^{-1}$, which indicates that the $\mathrm{MoS}_{2}$ sample is a single layer. Figure $3 \mathrm{~b}$ is the power Raman spectrum of $\mathrm{MoS}_{2}$, the peak intensities of $E^{1}{ }_{2 g}$ and $A_{1 g}$ characteristic peaks accordingly increase with the laser power increases and the peak position of $\mathrm{A}_{1 \mathrm{~g}}$ characteristic peaks is blue-shifted to some extent.
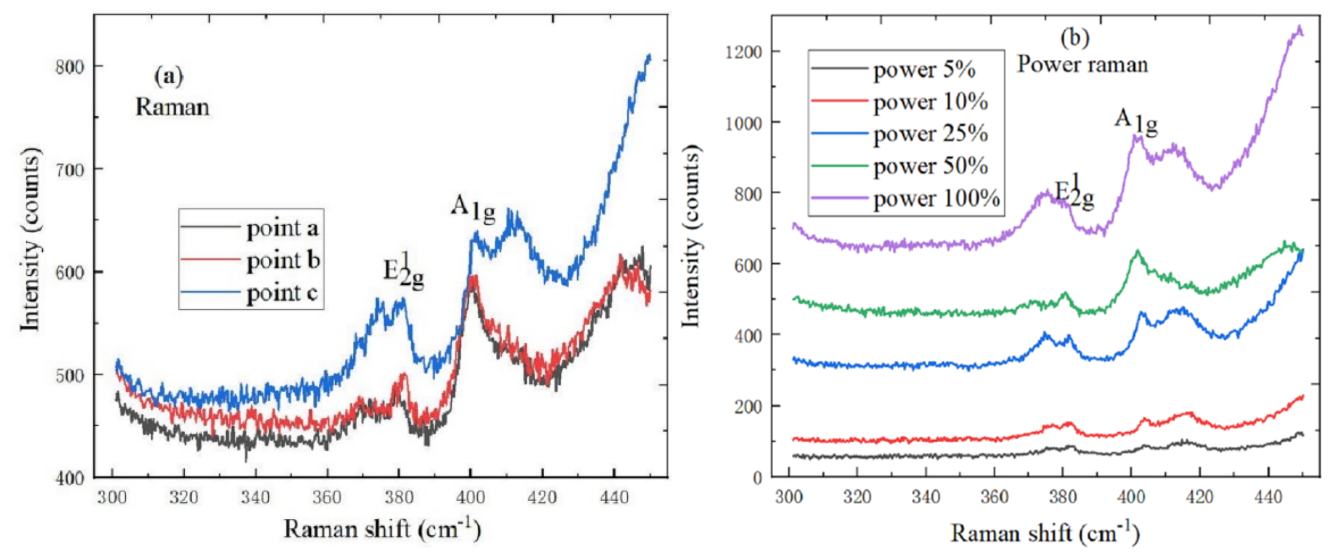

Figure 3. Spectral characteristics of $\mathrm{MoS}_{2}$. (a) Raman spectrum $(10 \mathrm{~mW}, 633 \mathrm{~nm})$ at different positions, (b) power Raman spectrum ( $1 \mathrm{~mW}, 2 \mathrm{~mW}, 5 \mathrm{~mW}, 10 \mathrm{~mW}, 20 \mathrm{~mW}$ and $633 \mathrm{~nm})$.

Figure 4a shows the Raman spectrum of monolayer $\mathrm{WS}_{2}$, the $\mathrm{E}^{1}{ }_{2 \mathrm{~g}}$ and $\mathrm{A}_{1 \mathrm{~g}}$ mode characteristic peaks are respectively located at $351.5 \mathrm{~cm}^{-1}$ and $416.4 \mathrm{~cm}^{-1}$, the peak position difference is $64.9 \mathrm{~cm}^{-1}$, and there is no peak near $310 \mathrm{~cm}^{-1}$, which indicates the existence of monolayer $\mathrm{WS}_{2}$. It can be found by observing Figure $4 \mathrm{~b}$ that the laser power has a great influence on the peak position and intensity of the $\mathrm{E}^{1}{ }_{2 \mathrm{~g}}$ vibration characteristic peak and the peak position of $\mathrm{A}_{1 \mathrm{~g}}$ vibration mode characteristic peak remains unchanged. This is because the electron concentration changes as the laser power increases, and the increase of electron concentration could cause a reforming of the band gap.
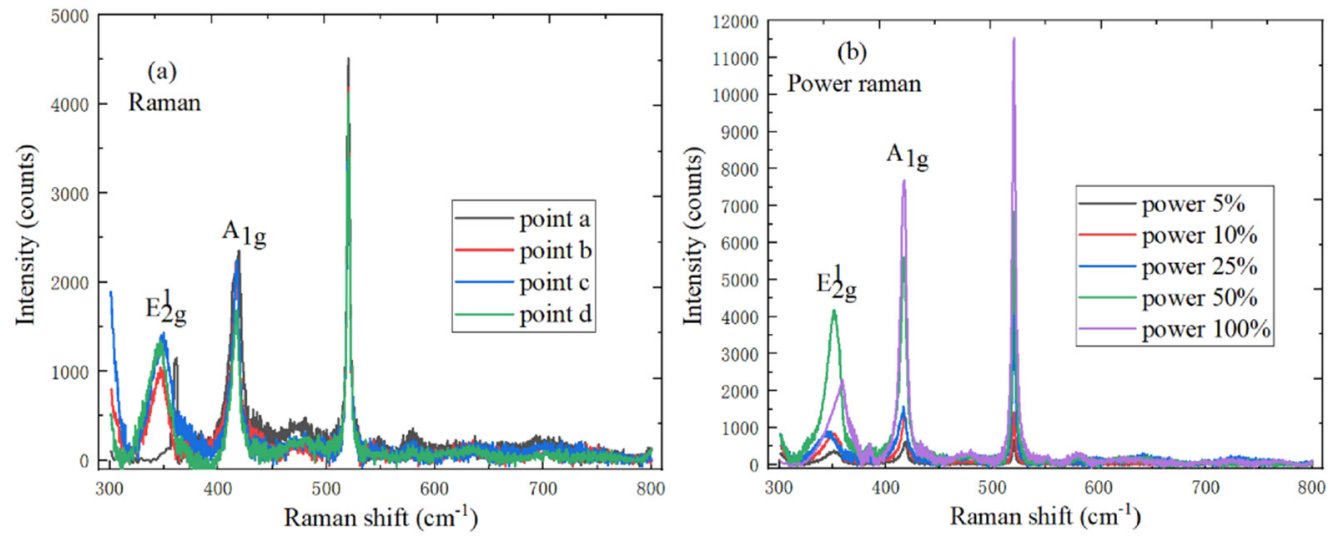

Figure 4. Spectral characteristics of $\mathrm{WS}_{2}$ (a) Raman spectrum $(10 \mathrm{~mW}, 633 \mathrm{~nm})$ at different positions; (b) power Raman spectrum ( $1 \mathrm{~mW}, 2 \mathrm{~mW}, 5 \mathrm{~mW}, 10 \mathrm{~mW}, 20 \mathrm{~mW}$ and $633 \mathrm{~nm}$ ). 


\subsection{The Test Experiment Results of $2 D-2 D$ vdWs Heterostructure Materials}

\subsubsection{The Characterization of $\mathrm{MoS}_{2} / \mathrm{h}-\mathrm{BN}$ Heterostructure}

In order to match the excitation energy to the PL spectrum exciton peak energy of $\mathrm{MoS}_{2}$ material, the resonance Raman scattering of $\mathrm{MoS}_{2} / \mathrm{h}-\mathrm{BN}$ heterostructure material can be studied by analyzing the band structure and exciton transition. Figure $5 \mathrm{a}, \mathrm{c}$ respectively represent the low-frequency ISM mode and high-frequency IPM mode characteristic peaks of $\mathrm{h}-\mathrm{BN}$, where the corresponding peaks are located at $53 \mathrm{~cm}^{-1}$ and $1358 \mathrm{~cm}^{-1}$.
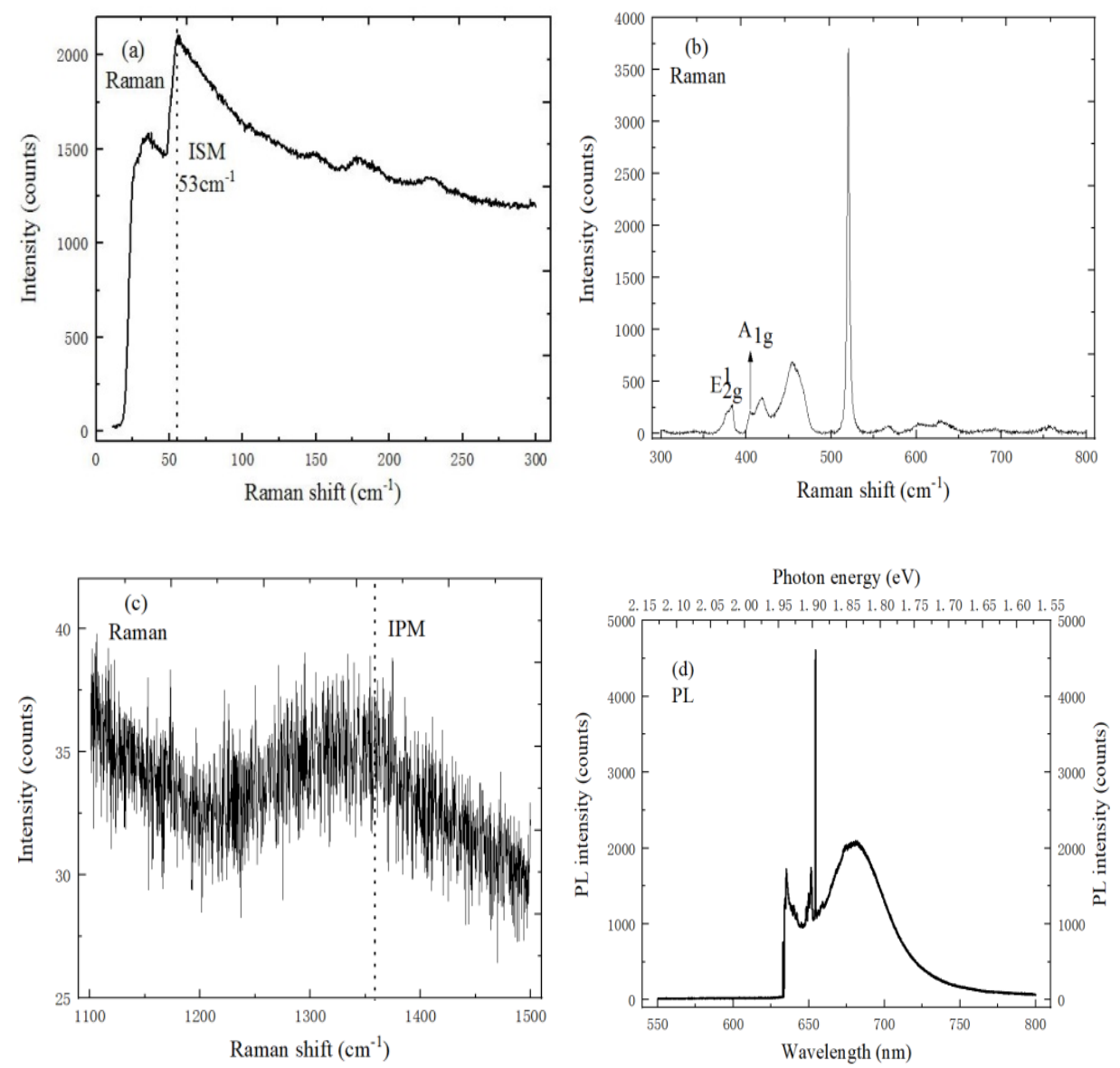

Figure 5. Spectral characteristics of $\mathrm{MoS}_{2} / \mathrm{h}-\mathrm{BN}$ heterostructure. (a) ISM mode characteristic peak of h-BN (10 mW, $633 \mathrm{~nm}),(\mathbf{b}) \mathrm{E}^{1}{ }_{2 \mathrm{~g}}$ and $\mathrm{A}_{1 \mathrm{~g}}$ mode characteristic peak of $\mathrm{MoS}_{2}(10 \mathrm{~mW}, 633 \mathrm{~nm})$, (c) IPM mode characteristic peak of h-BN $(10 \mathrm{~mW}, 633 \mathrm{~nm})$, (d) PL spectrum of $\mathrm{MoS}_{2} / \mathrm{h}-\mathrm{BN}$ heterostructure (20 mW, $633 \mathrm{~nm})$.

At the same time, the full width at half maxima (FWHM) of the IPM mode characteristic peak is much larger than that of the ISM mode. Figure $5 \mathrm{~b}$ shows the $\mathrm{E}^{1}{ }_{2 \mathrm{~g}}$ and $\mathrm{A}_{1 \mathrm{~g}}$ mode characteristic peaks of $\mathrm{MoS}_{2}$ on a h-BN substrate. The in-plane vibration $\mathrm{E}_{2 \mathrm{~g}}^{1}$ mode characteristic peak and out-plane vibration $\mathrm{A}_{1 \mathrm{~g}}$ mode characteristic peak are respectively located at $384.6 \mathrm{~cm}^{-1}$ and $404.2 \mathrm{~cm}^{-1}$, and the frequency difference is $19.6 \mathrm{~cm}^{-1}$. Compared with the Raman spectrum of $\mathrm{MoS}_{2}$ on $\mathrm{SiO}_{2} / \mathrm{Si}$ substrate, the characteristic peak frequencies of $E^{1}{ }_{2 g}$ mode and $A_{1 g}$ mode are respectively blue-shifted by $2.5 \mathrm{~cm}^{-1}$ and $2.8 \mathrm{~cm}^{-1}$ on $\mathrm{h}-\mathrm{BN} / \mathrm{SiO}_{2} / \mathrm{Si}$ substrate, and the substrate effect can explain the blue shift of the Raman peak on h-BN. Therefore, Raman spectroscopy at room temperature showed that the h-BN substrate can reduce the local strain and injected impurities into $\mathrm{MoS}_{2}$. Besides, the PL spectrum can be fitted by the Lorentz function, as shown in Figure $5 \mathrm{~d}$. The strongest PL peak position of $\mathrm{MoS}_{2}$ is at $681 \mathrm{~nm}$, and the corresponding energy electron volt band gap is $1.82 \mathrm{eV}$, which is consistent with the band gap of monolayer $\mathrm{MoS}_{2}$. The PL exciton emission of $\mathrm{MoS}_{2} / \mathrm{h}-\mathrm{BN}$ heterostructure material is two times larger than that of $\mathrm{MoS}_{2}$ material, 
and the FWHM is $26.39 \mathrm{~nm}$, which is narrower than that of $\mathrm{MoS}_{2}$ material. Therefore, $\mathrm{MoS}_{2} / \mathrm{h}-\mathrm{BN}$ heterostructure material has a tighter interlayer contact and lower charged impurities levels.

\subsubsection{The Characterization of $\mathrm{MoS}_{2} /$ Graphene Heterostructure}

When monolayer $\mathrm{MoS}_{2}$ material is grown directly on graphene to form a $\mathrm{MoS}_{2} /$ graphene heterostructure, their lattice vibrations would inevitably affect each other. In a $\mathrm{MoS}_{2}$ /graphene heterostructure, the work function of graphene is smaller than that of $\mathrm{MoS}_{2}$ material, which is beneficial to the formation of contacts.

In Figure $6 \mathrm{a}$, the $\mathrm{E}_{2 \mathrm{~g}}^{1}$ and $\mathrm{A}_{1 \mathrm{~g}}$ modes characteristic peaks of $\mathrm{MoS}_{2}$ material and the $\mathrm{G}$ and $2 \mathrm{D}$ peaks of graphene appear in the Raman spectrum, which indicates the presence of $\mathrm{MoS}_{2}$ /graphene heterostructures. Among them, the $\mathrm{E}^{1}{ }_{2 \mathrm{~g}}$ and $\mathrm{A}_{1 \mathrm{~g}}$ mode characteristic peak positions of $\mathrm{MoS}_{2}$ material are respectively located at $382.6 \mathrm{~cm}^{-1}$ and $400.3 \mathrm{~cm}^{-1}$, and the $G$ and 2D peak positions of graphene are located at $1602.5 \mathrm{~cm}^{-1}$ and $2689.7 \mathrm{~cm}^{-1}$, respectively. The $\mathrm{G}$ and $2 \mathrm{D}$ peak positions of the $\mathrm{MoS}_{2} /$ graphene heterostructure shift to larges wavenumbers compared with the spectrum of intrinsic graphene, the the $G$ and 2D peaks respectively change from $1585.9 \mathrm{~cm}^{-1}$ and $2631.3 \mathrm{~cm}^{-1}$ to $1602.5 \mathrm{~cm}^{-1}$ and $2689.7 \mathrm{~cm}^{-1}$. The reason is that the hole concentration becomes smaller and the electrons from $\mathrm{MoS}_{2}$ material can be transferred to the graphene. Besides, the $\mathrm{E}^{1}{ }_{2 \mathrm{~g}}$ and $\mathrm{A}_{1 \mathrm{~g}}$ mode characteristic peaks of $\mathrm{MoS}_{2}$ /graphene heter-structure are respectively red-shifted and blue-shifted by $0.5 \mathrm{~cm}^{-1}$ and $1.1 \mathrm{~cm}^{-1}$ compared with the spectrum of monolayer $\mathrm{MoS}_{2}$, which is due to the Van der Waals force interactions between $\mathrm{MoS}_{2}$ and graphene. Figure $6 \mathrm{~b}$ shows the PL spectrum of $\mathrm{MoS}_{2}$ /graphene heterostructure material at different positions. The strongest PL spectrum peak position of $\mathrm{MoS}_{2} /$ graphene heterostructure is at $674 \mathrm{~nm}$, and the corresponding electron volt energy is $1.84 \mathrm{eV}$. The peak position of strongest PL spectrum shows the blue shift, graphene has the influence on the Raman spectrum of $\mathrm{MoS}_{2}$ material. The energy band of $\mathrm{MoS}_{2}$ material bends downward, and the Schottky barrier is lower when the Fermi level of graphene and $\mathrm{MoS}_{2}$ materials are aligned. It can be found by observing Figure $6 \mathrm{c}$ that the intensity of characteristic peaks also increases with the laser power increases, and the positions of characteristic peaks shift. This is because as the test temperature of $\mathrm{MoS}_{2}$ /graphene heterostructure becomes higher, it will cause the spectrum to change. The rise of $2 \mathrm{D}$ and $\mathrm{G}$ peaks position is related to the effective interlayer coupling of $\mathrm{MoS}_{2}$ nanosheets, and the strain effect, which is caused by the high temperature heating. Besides, due to the PL phenomenon of $\mathrm{MoS}_{2}$, the background Raman signal increases with the wavenumber increase. As shown in Figure $6 d$, the peak intensity of strongest PL spectrum increases with the increase of laser power, and the corresponding peak positions shift. This is because the spectrum changes with temperature. In addition, the 2D peak of $\mathrm{MoS}_{2}$ /graphene heterostructure is superimposed on B exciton, and the peak position has the blue shift, which can be explained by the stacking effect [28]. Figure 6e shows the Raman spectrum comparison between $\mathrm{MoS}_{2}$ sample directly grown on a graphene and $\mathrm{MoS}_{2}$ sample transferred on a graphene substrate. The $\mathrm{E}^{1}{ }_{2 \mathrm{~g}}$ peak position of monolayer $\mathrm{MoS}_{2}$ material is blue-shifted by $1.3 \mathrm{~cm}^{-1}$ after the transfer, and the $\mathrm{A}_{1 \mathrm{~g}}$ peak position only changes slightly. There is a certain tension effect when monolayer $\mathrm{MoS}_{2}$ material is grown on the $\mathrm{SiO}_{2} / \mathrm{Si}$ substrate by CVD. After the transfer, the A1 peak position of PL spectrum in $\mathrm{MoS}_{2}$ sample has a blue shift about $40 \mathrm{meV}$, as shown in Figure 6f. The peak intensity of PL spectrum in $\mathrm{MoS}_{2}$ sample transferred on a graphene is higher than that of $\mathrm{MoS}_{2}$ sample directly grown on a graphene. The reason is that the tension of the sample is effectively released while using PMMA to transfer $\mathrm{MoS}_{2}$ material to the new $\mathrm{SiO}_{2} / \mathrm{Si}$ substrate. 

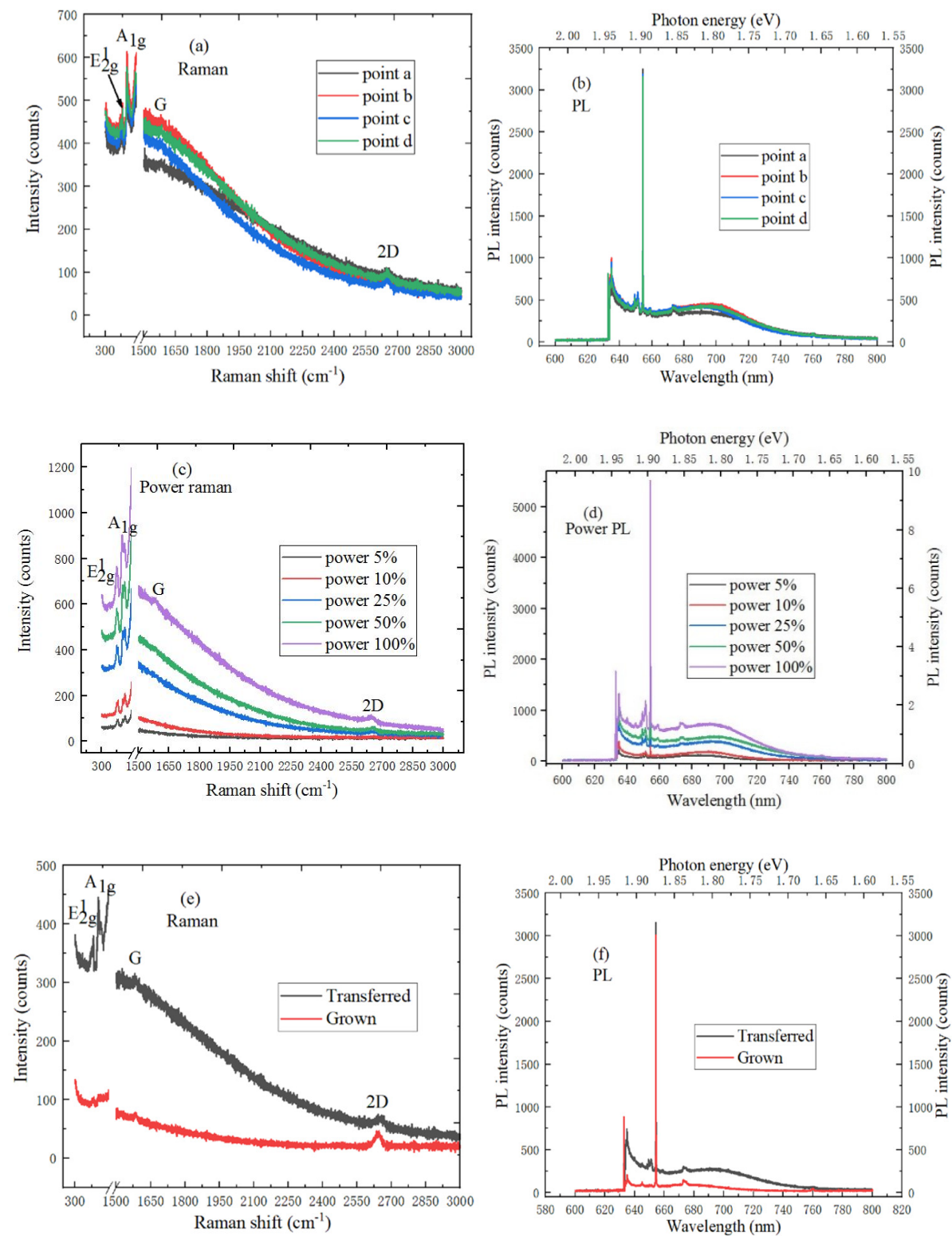

Figure 6. Spectral characteristics of $\mathrm{MoS}_{2}$ /graphene heterostructure. (a) Raman spectrum (10 mW, $633 \mathrm{~nm})$ and (b) PL spectrum $(20 \mathrm{~mW}, 633 \mathrm{~nm})$ at different positions; (c) power Raman spectrum $(1 \mathrm{~mW}, 2 \mathrm{~mW}, 5 \mathrm{~mW}, 10 \mathrm{~mW}, 20 \mathrm{~mW}$ and $633 \mathrm{~nm})$, (d) power PL spectrum $(1 \mathrm{~mW}, 2 \mathrm{~mW}, 5 \mathrm{~mW}$, $10 \mathrm{~mW}, 20 \mathrm{~mW}$ and $633 \mathrm{~nm})$; (e) Raman spectrum (10 mW, $633 \mathrm{~nm})$ and (f) PL spectrum (20 mW, 633 $\mathrm{nm}$ ) comparison between $\mathrm{MoS}_{2}$ sample directly grown on a graphene and $\mathrm{MoS}_{2}$ sample transferred on a graphene.

A $633 \mathrm{~nm}$ red laser was used to compare and analyze the spectral characteristics of $\mathrm{MoS}_{2}$ on h-BN and graphene substrates. As we all know, the $\mathrm{MoS}_{2}$ material has a suitable and adjustable band gap, strong exciton interaction, unique nonlinear effects and a novel spin valley effect, which has the great application potential in the fields of integrated electronic chips, photoelectric conversion and the energy environment. In Figure 7a, the $\mathrm{E}^{1}{ }_{2 \mathrm{~g}}$ and $\mathrm{A}_{1 \mathrm{~g}}$ mode characteristic peaks of $\mathrm{MoS}_{2}$ /graphene heterostructure are blue-shifted relative to the $\mathrm{MoS}_{2} / \mathrm{h}-\mathrm{BN}$ heterostructure material. The reason is that the graphene substrate has the effect on the Raman spectrum of $\mathrm{MoS}_{2}$. Vertical heterostructures can be formed by the van der Waals force between the upper and lower layers, which would lead to a strong quantum confinement effect. This can not only change the electronic band and optical properties of $\mathrm{MoS}_{2}$ material, but also give it more excellent chemical activity. It can be found from Figure $7 \mathrm{~b}$ that the strongest PL peak position of $\mathrm{MoS}_{2} /$ graphene 
heterostructure material is red-shifted compared with $\mathrm{MoS}_{2} / \mathrm{h}$-BN heterostructure, and the peak intensity is weaker than that of $\mathrm{MoS}_{2} / \mathrm{h}-\mathrm{BN}$ heterostructure. This is because graphene has the weakening effect on the fluorescence of $\mathrm{MoS}_{2}$. Besides, the exciton absorption peak of PL spectrum in $\mathrm{MoS}_{2} /$ graphene heterostructure is located at $621 \mathrm{~nm}$. The change of thickness and the abundance of heterostructures can further produce and broaden the new characteristics and application research of $\mathrm{MoS}_{2}$ material.
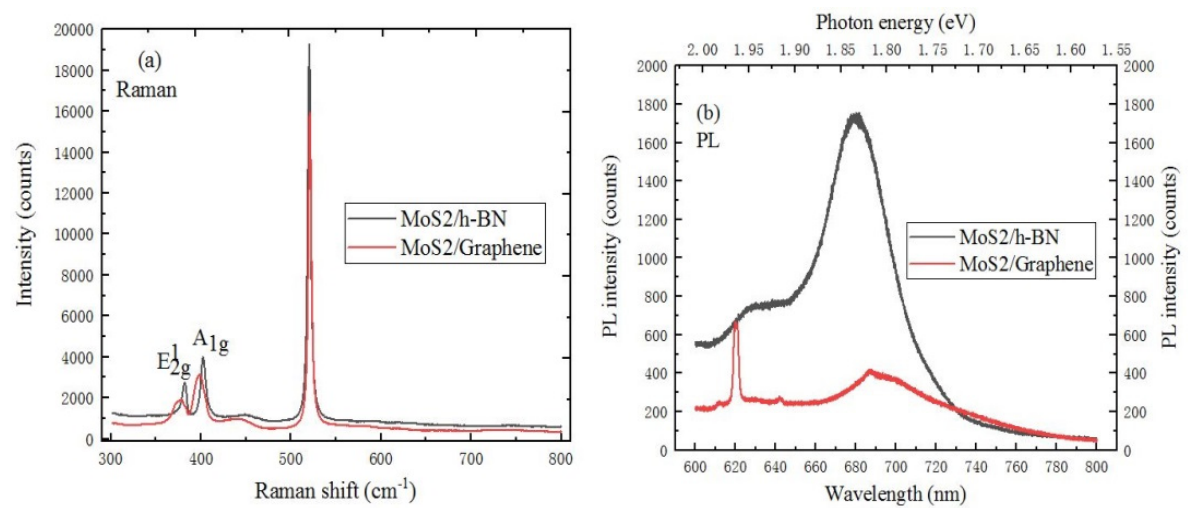

Figure 7. Spectral characteristics of $\mathrm{MoS}_{2}$ on h-BN and graphene substrate (a) Raman spectrum (10 mW, $633 \mathrm{~nm})$, (b) PL spectrum $(20 \mathrm{~mW}, 633 \mathrm{~nm})$.

\subsubsection{The Characterization of $\mathrm{WS}_{2} / \mathrm{hBN}$ Heterostructure}

Figure 8 a,c respectively show the ISM and IPM mode characteristic peaks of $\mathrm{WS}_{2} / \mathrm{h}$ BN heterostructure materials where the corresponding peak positions are located at $52 \mathrm{~cm}^{-1}$ and $1346 \mathrm{~cm}^{-1}$, respectively.
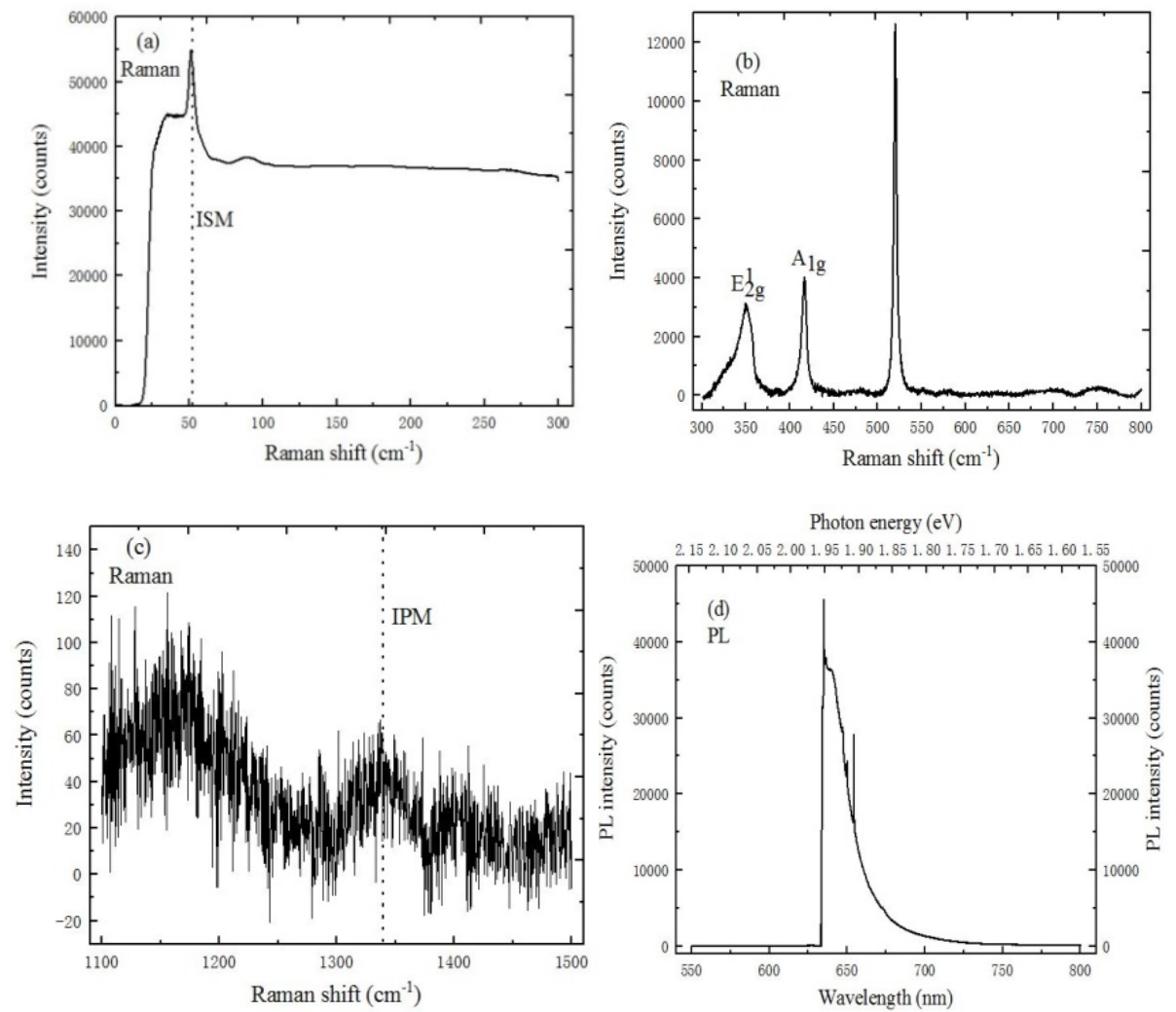

Figure 8. Spectral characteristics of $\mathrm{WS}_{2} / \mathrm{h}-\mathrm{BN}$ heterostructure. (a) ISM mode characteristic peak of h-BN (10 mW, $633 \mathrm{~nm}),(\mathbf{b}) \mathrm{E}^{1}{ }_{2 \mathrm{~g}}$ and $\mathrm{A}_{1 \mathrm{~g}}$ mode characteristic peaks of $\mathrm{WS}_{2}(10 \mathrm{~mW}, 633 \mathrm{~nm})$, (c) IPM mode characteristic peak of h-BN $(10 \mathrm{~mW}, 633 \mathrm{~nm})$, (d) PL spectrum of $\mathrm{WS}_{2} / \mathrm{h}-\mathrm{BN}$ heterostructure $(20 \mathrm{~mW}, 633 \mathrm{~nm})$. 
Compared to the spectrum of $\mathrm{MoS}_{2} / \mathrm{h}-\mathrm{BN}$ heterostructure, the peak position of ISM and IPM mode characteristic peaks are blue-shifted. The reason is that $\mathrm{WS}_{2}$ material has an influence on the spectrum of h-BN. It can be clearly observed from Figure $8 \mathrm{~b}$ that the $\mathrm{E}^{1}{ }_{2 \mathrm{~g}}$ and $\mathrm{A}_{1 \mathrm{~g}}$ Raman activation mode peak positions of $\mathrm{WS}_{2}$ are respectively located at $354.8 \mathrm{~cm}^{-1}$ and $419.4 \mathrm{~cm}^{-1}$, and the peak spacing is $64.6 \mathrm{~cm}^{-1}$, which corresponds to the peak spacing of monolayer $\mathrm{WS}_{2}$ on $\mathrm{SiO}_{2} / \mathrm{Si}$ substrate. The peak position of $\mathrm{WS}_{2} / \mathrm{h}$-BN heterostructure is different from that of $\mathrm{WS}_{2}$ on $\mathrm{SiO}_{2} / \mathrm{Si}$ substrate. The reason is that the van der Waals interaction between layers, and the effective transfer between dielectric screen of long-distance Coulomb interactions. In Figure 8d, the peak position of the strong peak is located at $1.95 \mathrm{eV}$. Meanwhile, the FWHM of PL emission peak is less than that of $\mathrm{WS}_{2}$ material. The FWHM of PL emission peak is related to the exciton lifetime and interface quality, which can be attributed to the extension of high crystallinity $\mathrm{WS}_{2}$ material, and the clean heterojunction interface.

\subsubsection{The Characterization of $\mathrm{WS}_{2} /$ Graphene Heterostructure}

Raman spectroscopy is used to evaluate the crystal quality and film thickness of 2D materials. The Raman spectrum contrast analysis of $\mathrm{WS}_{2}$ and $\mathrm{WS}_{2}$ /graphene heterostructures is shown in Figure 9a, the peak position of $\mathrm{A}_{1 \mathrm{~g}}$ mode characteristic peak of $\mathrm{WS}_{2} /$ graphene heterostructure shifts to the short wavelength compared with the Raman spectrum of $\mathrm{WS}_{2}$, and the peak position of $A_{1 g}$ characteristic peak has the blue shift. And the $E_{2 g}^{1}$ and $A_{1 g}$ mode characteristic peak intensity of $\mathrm{WS}_{2}$ /graphene heterostructure is higher than that of $\mathrm{WS}_{2}$.
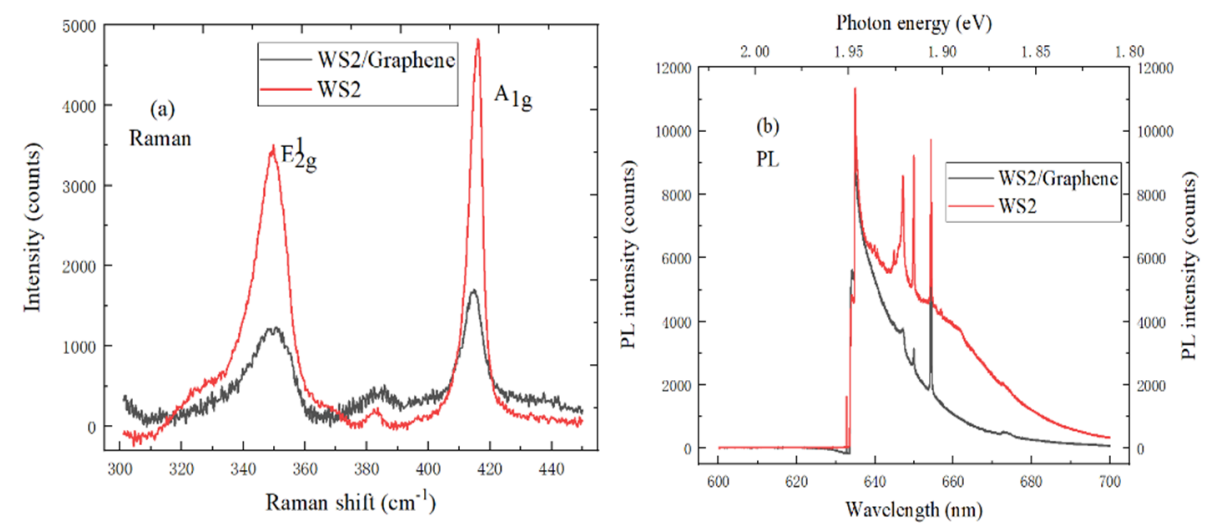

Figure 9. (a) Raman spectrum (10 mW, $633 \mathrm{~nm})$, (b) PL spectrum $(20 \mathrm{~mW}, 633 \mathrm{~nm})$ characteristics comparison of $\mathrm{WS}_{2}$ and $\mathrm{WS}_{2}$ /graphene heterostructure.

There is the sharp Raman characteristic peak, which indicates that $\mathrm{WS}_{2}$ /graphene heterostructure film has excellent crystallinity. In addition, monolayer $\mathrm{WS}_{2}$ and multilayer $\mathrm{WS}_{2}$ materials are respectively the direct bandgap semiconductor and indirect semiconductor, so the PL spectroscopy can also be used to identify the number of layers. In Figure $9 \mathrm{~b}$, the PL spectrum of $\mathrm{WS}_{2}$ and $\mathrm{WS}_{2}$ /graphene heterostructure both show the strongest PL emission peak is located at $634 \mathrm{~nm}$, and the band gap is about $1.94 \mathrm{eV}$, which indicates that it is consistent with a mechanically peeled monolayer $\mathrm{WS}_{2}$. The PL intensity of $\mathrm{WS}_{2}$ /graphene heterostructure is weaker than that of monolayer $\mathrm{WS}_{2}$. This is because the work function between graphene and $\mathrm{WS}_{2}$ material does not match, thus forming the internal field, which would cause the photoelectrons from $\mathrm{WS}_{2}$ can transfer to graphene, and leave holes in $\mathrm{WS}_{2}$.

In Figure 10a, the typical G peak and 2D peak of intrinsic graphene were respectively located at $1583.5 \mathrm{~cm}^{-1}$ and $2667.5 \mathrm{~cm}^{-1}$, and the intensity of $2 \mathrm{D}$ peak is almost twice that of $\mathrm{D}$ peak, which indicates the presence of monolayer graphene. The $\mathrm{D}$ peak appears in the Raman spectrum of graphene material when the growth of $\mathrm{WS}_{2}$ material is completed. Meanwhile, the peak position of 2D peak shifts downward, which is due to the effective interlayer coupling and strain effect. As shown in Figure 10b, the background Raman 
signal of PL spectrum increases with the increase of wavenumber, which is attributed to the PL phenomenon of $\mathrm{WS}_{2}$. At the same time, the internal field can be formed, which is due to the work function mismatch between graphene and $\mathrm{WS}_{2}$.
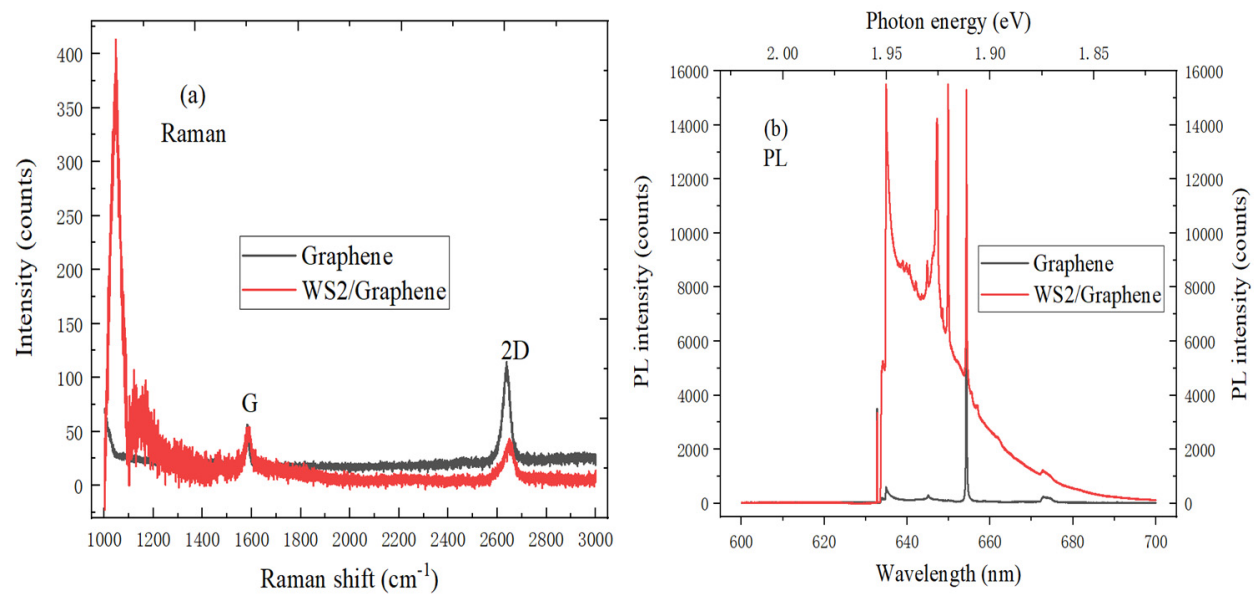

Figure 10. (a) Raman spectrum (10 mW, $633 \mathrm{~nm})$, (b) PL spectrum (20 mW, $633 \mathrm{~nm})$ comparison of graphene and $\mathrm{WS}_{2}$ /graphene heterostructure.

A Raman spectrum characteristics comparison of $\mathrm{WS}_{2} / \mathrm{h}-\mathrm{BN}$ and $\mathrm{WS}_{2} /$ graphene heterostructure is shown in Figure 11a. Compared to the spectrum of $\mathrm{WS}_{2} / \mathrm{h}$-BN heterostructure, the $\mathrm{E}^{1}{ }_{2 \mathrm{~g}}$ and $\mathrm{A}_{1 \mathrm{~g}}$ mode characteristic peaks of $\mathrm{WS}_{2} /$ graphene heterostructure are respectively red-shifted and blue-shifted. The reason is that graphene material has a influence on the spectrum of $\mathrm{WS}_{2}$ material. In Figure 11b, the strongest PL peak position of $\mathrm{WS}_{2}$ /graphene heterostructure is blue shifted. The difference of peak position shift can be attributed to the influence of different substrates and the change of interaction.
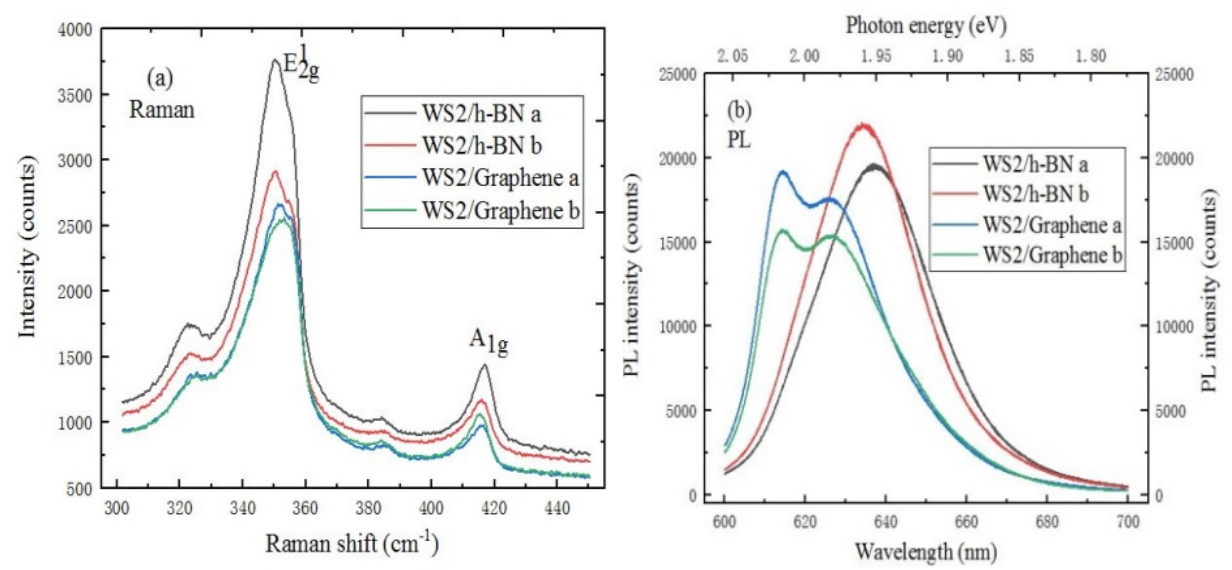

Figure 11. (a) Raman spectrum (10 mW, $633 \mathrm{~nm})$, (b) PL spectrum (20 mW, $633 \mathrm{~nm})$ comparison of $\mathrm{WS}_{2}$ on $\mathrm{h}-\mathrm{BN} / \mathrm{SiO}_{2} / \mathrm{Si}$ or graphene $/ \mathrm{SiO}_{2} / \mathrm{Si}$ substrate.

\section{Materials and Methods}

\subsection{Preparation of Graphene and h-BN Materials}

First, the copper foil substrate was used in the growth process of graphene and h-BN materials by the CVD growth process. Before the growth of graphene and h-BN films on copper foil substrate, it is necessary to immerse the copper substrate in hydrochloric acid for $15 \mathrm{~min}$ to remove the local surface oxides. Finally, the copper foil substrate can be rinsed with the acetone and isopropanol solution.

Figure 12a shows the preparation schematic diagram of graphene. First, the cleaned copper substrate was placed in a CVD furnace. Then, the chamber was evacuated to the 
vacuum pressure of 1 mTorr to remove any harmful gases. Finally, the chamber of tube furnace can restore the atmospheric pressure by filling the chamber with dilute argon gas diluted with $5 \%$ hydrogen. The following describes the main growth processes of graphene material. First, the copper foil substrate of tube furnace was annealed, the maximum temperature and annealing time were set to $1050{ }^{\circ} \mathrm{C}$ and $30 \mathrm{~min}$ during the annealing process, and $30 \mathrm{sccm} \mathrm{H} \mathrm{H}_{2}$ was also punched. Next, the tube furnace was charged with $35 \mathrm{sccm} \mathrm{CH} \mathrm{CH}_{4}$, while the flow rate of $\mathrm{H}_{2}$ was adjusted to $10 \mathrm{sccm}$, and the growth time of graphene was $30 \mathrm{~min}$, as shown in Figure 12b. Finally, the tube furnace is cooled to room temperature by the forced cooling, which can also prevent the $\mathrm{CH}_{4}$ gas from flowing into the tube furnace.
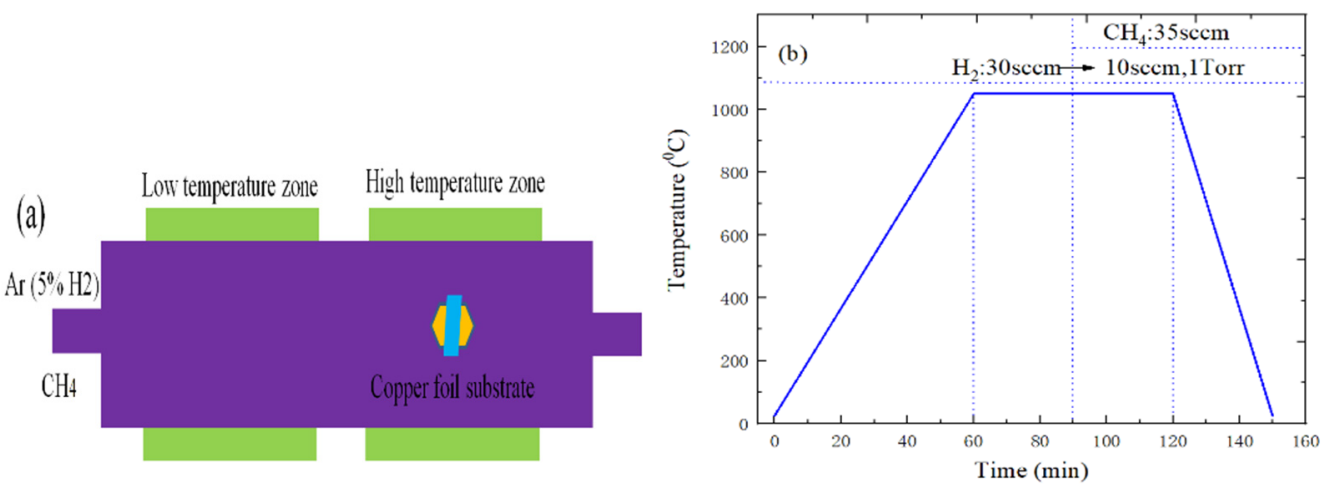

Figure 12. (a) the preparation schematic diagram of graphene; (b) temperature change curve of graphene.

Figure 13a is the preparation schematic diagram of h-BN on the copper foil substrate by CVD method. First, the tube furnace was heated to $1050{ }^{\circ} \mathrm{C}$, and the copper foil substrate was annealed and recrystallized at the temperature for $30 \mathrm{~min}$. Then, while entering the growth stage, the ammonia borane can decompose to form the hydrogen $\left(\mathrm{H}_{2}\right.$ gas), aminoborane polymer (aminoborane) and borazine under the action of heating belt [29]. At the same time, boron azepine enters the high temperature heating area of tube furnace under the carrier gas action of $10 \mathrm{sccm} \mathrm{H}$. Next, the borazine can dehydrogenated again due to the catalytic effect of the copper foil metal, and the $\mathrm{B}$ and $\mathrm{N}$ atoms combined to form h-BN on $\mathrm{SiO}_{2}$ / Si substrate. Finally, the power supply of heating belt and furnace is quickly cut off when the h-BN growth reaction is completed, and the tube furnace enters the cooling stage. The specific temperature change curve is shown in Figure $13 \mathrm{~b}$.

(a) Low temperature zone High temperature zone
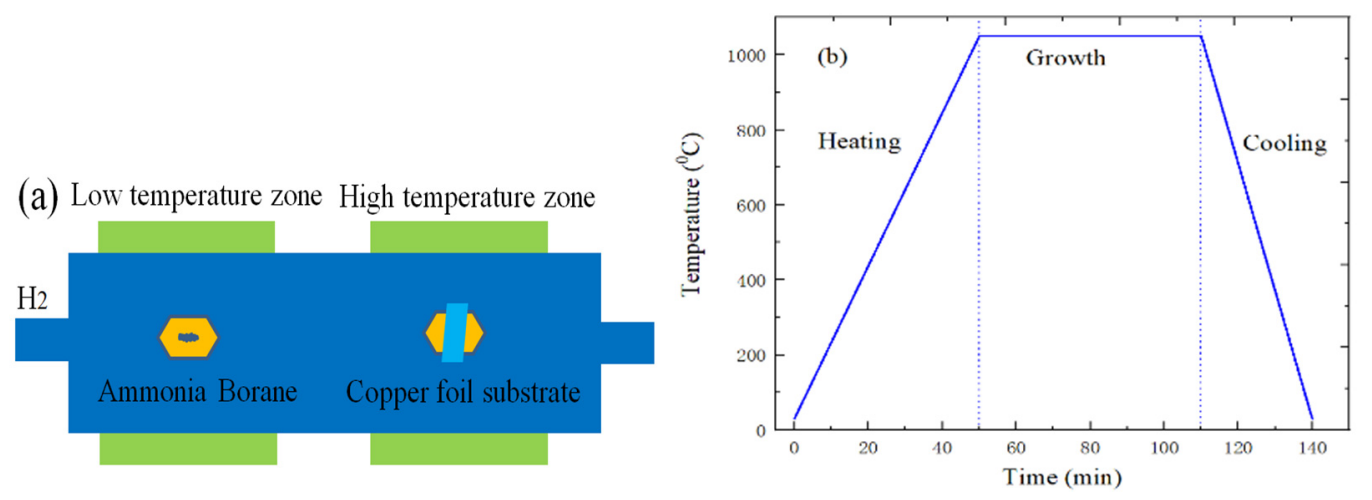

Figure 13. (a) the growth schematic diagram of h-BN; (b) CVD growth temperature change curve of h-BN.

\subsection{The Transfer of Graphene or h-BN}

The graphene or h-BN material grown on $\mathrm{Cu}$ foil substrate by CVD method was transferred to $\mathrm{SiO}_{2} / \mathrm{Si}$ substrate, which can be achieved by the PMMA transfer method. 
First, the $500 \mathrm{~nm}$ PMMA layer was spin-coated on the graphene or h-BN/copper foil substrate, and the PMMA film was cured at $120^{\circ} \mathrm{C}$ for $3 \mathrm{~min}$ when the spin coating was completed. Then, the copper foil substrate was etched by $1 \mathrm{M} \mathrm{FeCl}_{3}$ solution. Next, the PMMA/graphene or PMMA/h-BN layers were rinsed several times in deionized water, which can be transferred to the $\mathrm{SiO}_{2} / \mathrm{Si}$ substrate. Subsequently, the sample was dried in the $\mathrm{N}_{2}$ gas environment for $12 \mathrm{~h}$ to make the graphene or $\mathrm{h}-\mathrm{BN}$ and $\mathrm{SiO}_{2} / \mathrm{Si}$ substrate adhere more closely. Immediately after, the PMMA film was washed away in the acetone solution.

\subsection{The Preparation of $\mathrm{WS}_{2}$ or $\mathrm{MoS}_{2}$ Material}

The purpose of oxygen plasma treatment is to make the $\mathrm{SiO}_{2} / \mathrm{Si}$ substrate hydrophilic, and the treatment is $2 \mathrm{~min}$, which can help the transfer of graphene or h-BN film and the growth of $\mathrm{MoS}_{2}$ or $\mathrm{WS}_{2}$ materials [30]. The $\mathrm{SiO}_{2} / \mathrm{Si}$ substrate was annealed at $400{ }^{\circ} \mathrm{C}$ for $8 \mathrm{~h}$ when graphene or h-BN thin film was transferred to $\mathrm{SiO}_{2} / \mathrm{Si}$ substrate. Meanwhile, the Ar gas with $5 \% \mathrm{H}_{2}$ was continuously provided to remove residues during the transfer process.

The $\mathrm{WS}_{2}$ or $\mathrm{MoS}_{2}$ materials were grown on the graphene $/ \mathrm{SiO}_{2} / \mathrm{Si}$ or h-BN$/ \mathrm{SiO}_{2} / \mathrm{Si}$ substrate in the tube furnace, and the $\mathrm{SiO}_{2} / \mathrm{Si}$ samples coated with graphene or h-BN materials were used as the substrates. The quartz boat containing $200 \mathrm{mg}$ sulfur powder was placed upstream of the tube furnace, which is the low-temperature heating zone. At the same time, the graphene $/ \mathrm{SiO}_{2} / \mathrm{Si}$ or h-BN$/ \mathrm{SiO}_{2} / \mathrm{Si}$ substrate were placed upside down on the quartz boat containing $\mathrm{WO}_{3}$ or $\mathrm{MoO}_{3}$ powder, which is located in the high temperature heating area of tube furnace, as shown in Figure 14a. It can be found from Figure $14 \mathrm{~b}$ that the temperature of sulfur powder and $\mathrm{MoO}_{3}$ powder (or $\mathrm{WO}_{3}$ powder) respectively rises to $50{ }^{\circ} \mathrm{C}, 100^{\circ} \mathrm{C}, 100^{\circ} \mathrm{C}$ within $5 \mathrm{~min}$, and maintains at this temperature for $10 \mathrm{~min}$. Next, the temperature of sulfur powder and $\mathrm{MoO}_{3}$ powder (or $\mathrm{WO}_{3}$ powder) can respectively reach the sublimation temperature of $150{ }^{\circ} \mathrm{C}, 800{ }^{\circ} \mathrm{C}$ and $950{ }^{\circ} \mathrm{C}$ within $50 \mathrm{~min}$, and the growth temperature is maintained for $10 \mathrm{~min}$. Finally, the tube furnace was naturally cooled to room temperature.
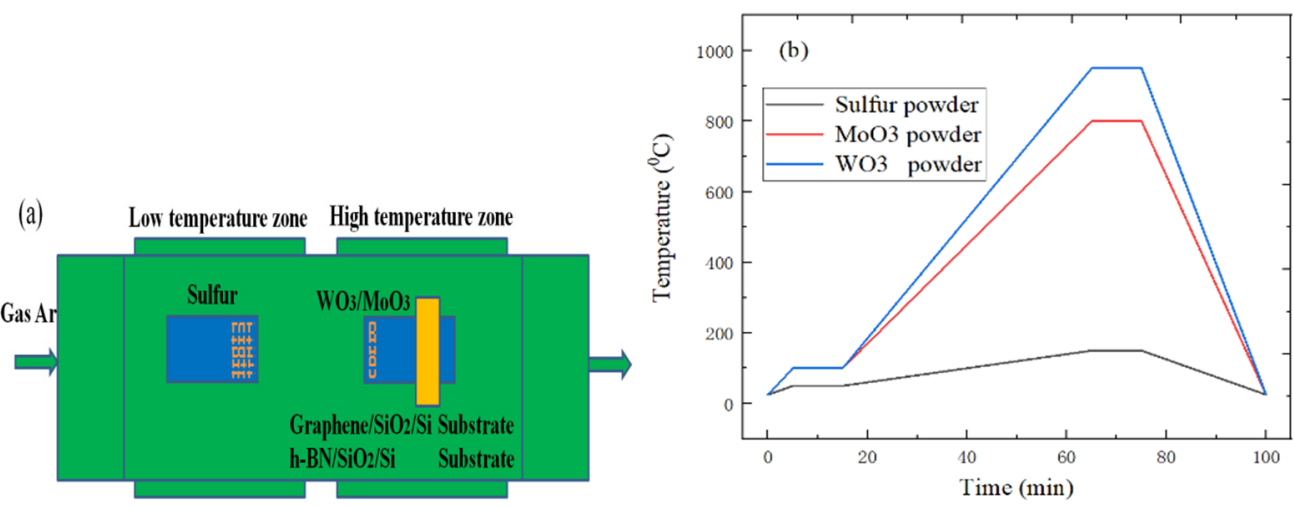

Figure 14. (a) Experimental schematic diagram of $\mathrm{WS}_{2}$ and $\mathrm{MoS}_{2}$ growth; (b) The relationship between temperature and time in different heating zones.

\subsection{The Test Characterization of Heterojunction Materials}

Raman spectrometry can confirm the molecular structure by the Raman shift. The incident light is scattered when a certain wavelength of laser is irradiated on the sample surface, and the frequency of most scattered light does not change, which is the Rayleigh scattering. The small part scattering of scattered light frequency is referred to as Raman scattering, and the frequency difference between scattered light and incident light is called Raman shift. Raman spectroscopy is used to monitor the crystal quality, polymorphism, doping, defects, strain, disorder, chemical modification and relative orientation of $2 \mathrm{D}$ materials. Besides, Raman analysis has the high spatial resolution, the fast and easy spectral imaging, which is suitable for identifying the characteristics and structure of 
various materials [31]. The photoluminescence (PL) spectrum is that the sample can obtain the energy while being irradiated by an external light source, which can produce the excitation light emission phenomenon. The internal information of material samples can be obtained by the research and analysis of PL spectroscopy, which can guide the analysis of sample quality, defect distribution information.

The distribution of heterostructure samples on the substrate surface can be observed by optical microscopy, which can test and characterize the aboveprepared heterostructure materials. The spatial resolution depends on the choice of excitation laser to a certain extent, and the excitation wavelength can be optimized based on the characteristics of the sample. Meanwhile, a Raman spectrometer (LabRam HR Evolution, HORIBA Jobin Yvon, Paris, France) with a $633 \mathrm{~nm}$ laser red light was used to measure and obtain the single-point Raman and PL spectrum of the heterostructure materials, and the surface uniformity and composition distribution of heterostructure film were analyzed by Raman and fluorescence surface scanning. The surface morphology of heterostructure materials can be observed by optical microscopy. For the Raman and PL spectrum tests, the corresponding laser power is respectively fixed at $10 \mathrm{~mW}$ and $20 \mathrm{~mW}$, the laser spot diameter is $1 \mu \mathrm{m}$, and the objective magnification of microscope is 10 . The Raman data of characteristic peaks were analyzed by the classical least squares (CLS) fitting.

\section{Conclusions}

$\mathrm{MoS}_{2} / \mathrm{h}-\mathrm{BN}, \mathrm{MoS}_{2} /$ graphene, $\mathrm{WS}_{2} / \mathrm{h}-\mathrm{BN}$ and $\mathrm{WS}_{2} /$ graphene van der Waals heterostructures were successfully prepared in this paper. The growth mechanism and optical characteristics of heterostructure materials can be studied by optical contrast microscopy and Raman PL spectroscopy, which can obtain the spectral characteristics of heterostructure materials. These heterostructures exhibit the novel and unique optical properties at the stacking or junction of several materials. The Raman and PL spectroscopy models are complementary and can describe the temperature-dependent relationships between interlayer coupling and physical origin. Meanwhile, the electron-phonon coupling and $\mathrm{vdW}$ interaction can be enhanced by reducing the local strain and charged impurities. Compared with the Raman spectrum of $\mathrm{MoS}_{2}$ on $\mathrm{SiO}_{2} / \mathrm{Si}$ substrate, the characteristic peak frequencies of $\mathrm{E}_{2 \mathrm{~g}}^{1}$ mode and $\mathrm{A}_{1 \mathrm{~g}}$ mode are blue-shifted by $2.5 \mathrm{~cm}^{-1}$ and $2.8 \mathrm{~cm}^{-1}$ respectively on a h-BN/SiO $2 / S i$ substrate, and the $\mathrm{E}^{1}{ }_{2 \mathrm{~g}}$ and $\mathrm{A}_{1 \mathrm{~g}}$ mode characteristic peaks of $\mathrm{MoS}_{2}$ /graphene heterostructure are respectively red-shifted and blue-shifted by $0.5 \mathrm{~cm}^{-1}$ and $1.1 \mathrm{~cm}^{-1}$. The $\mathrm{G}$ and $2 \mathrm{D}$ peak positions of $\mathrm{MoS}_{2} /$ graphene heterostructure shift to the large wavenumber compared with the spectrum of intrinsic graphene. Besides, $\mathrm{E}^{1}{ }_{2 \mathrm{~g}}$ and $\mathrm{A}_{1 \mathrm{~g}}$ mode characteristic peaks of $\mathrm{MoS}_{2} /$ graphene heterostructure are blue-shifted compared with $\mathrm{MoS}_{2} / \mathrm{h}-\mathrm{BN}$ heterostructure, and the strongest peak position of PL spectrum is red-shifted. The crystal orientation between $\mathrm{WS}_{2}$ or $\mathrm{MoS}_{2}$ growth and $\mathrm{hBN}$ or a graphene substrate is significantly different, which is due to the interlayer Coulomb interactions. Our research can effectively improve the interlayer coupling basic understanding of heterostructures and temperature-dependent Raman and PL spectra were used to explore the optical properties of vdWs heterostructures. Therefore, nanoscale vdW heterostructures have the great application prospects in the fields of nanoelectronics and optoelectronics.

Author Contributions: Conceptualization, S.W. and S.C.; methodology, K.Y.; data curation, Z.L.; writing-original draft preparation, T.H.; writing—review and editing, H.L. and T.H.; funding acquisition, H.L. All authors have read and agreed to the published version of the manuscript.

Funding: This research was funded by the National Natural Science Foundation of China (Grant No. U1866212, and 61904136), the Fundamental Research Program of Shaanxi (Grant No. 2019JQ-656), and the Key Technologies Research on Multilevel Cooperative Suppression for Transient Electromagnetic Interference of Power Master control chip (Grant No. 546816190005). The results of this paper were also supported by the China Scholarship Council.

Institutional Review Board Statement: Not applicable.

Informed Consent Statement: Not applicable as the studies did not involve humans. 
Data Availability Statement: No new data were created or analyzed in this study. Data sharing is not applicable to this article.

Conflicts of Interest: The authors declare no conflict of interest.

\section{References}

1. Zhao, Y.J.; Zhang, X.W.; Wang, C.Z.; Zhao, Y.Z.; Zhou, H.P.; Li, J.B.; Jin, H.B. The synthesis of hierarchical nanostructured $\mathrm{MoS}_{2}$ /Graphene composites with enhanced visible-light photo-degradation property. Appl. Surf. Sci. 2017, 412, 207-213. [CrossRef]

2. Zhang, D.Q.; Jia, Y.X.; Cheng, J.Y.; Chen, S.M.; Chai, J.X.; Yang, X.Y.; Wu, Z.Y.; Wang, H.; Zhang, W.J.; Zhao, Z.L.; et al. Highperformance microwave absorption materials based on $\mathrm{MoS}_{2}$-graphene isomorphic hetero-structures. J. Alloy. Compd. 2018, 758, 62-71. [CrossRef]

3. Liu, M.X.; Shi, J.P.; Li, Y.C.; Zhou, X.B.; Ma, D.L.; Qi, Y.; Zhang, Y.F.; Liu, Z.F. Temperature-Triggered Sulfur Vacancy Evolution in Monolayer $\mathrm{MoS}_{2} /$ Graphene Heterostructures. Small 2017, 13, 1602967. [CrossRef] [PubMed]

4. Song, H.J.; Wang, B.; Zhou, Q.; Xiao, J.X.; Jia, X.H. Preparation and tribological properties of $\mathrm{MoS}_{2} /$ graphene oxide composites. Appl. Surf. Sci. 2017, 419, 24-34. [CrossRef]

5. Xie, Y.N.; Chou, T.M.; Yang, W.F.; He, M.H.; Zhao, Y.R.; Li, N.; Lin, Z.H. Flexible thermoelectric nanogenerator based on the $\mathrm{MoS}_{2}$ /graphene nanocomposite and its application for a self-powered temperature sensor. Semicond. Sci. Technol. 2017, 32, 044003. [CrossRef]

6. Liu, X.J.; Gao, J.F.; Zhang, G.; Zhang, Y.W. $\mathrm{MoS}_{2}$-graphene in-plane contact for high interfacial thermal conduction. Nano Res. 2017, 10, 2944-2953. [CrossRef]

7. Biroju, R.K.; Pal, S.; Sharma, R.; Giri, P.K.; Narayanan, T.N. Stacking sequence dependent photo-electrocatalytic performance of CVD grown MoS2/graphene van der Waals solids. Nanotechnology 2017, 28, 085101. [CrossRef]

8. $\quad$ Ding, L.; Ukhtary, M.S.; Chubarov, M.; Choudhury, T.H.; Zhang, F.; Yang, R.; Zhang, A.; Fan, J.A.; Terrones, M.; Redwing, J.M.; et al. Understanding interlayer coupling in TMD-HBN heterostructure by Raman spectroscopy. IEEE Trans. Electron Devices 2018, 65, 4059-4067. [CrossRef]

9. Xu, W.S.; Kozawa, D.; Zhou, Y.Q.; Wang, Y.Z.; Sheng, Y.W.; Jiang, T.; Strano, M.S.; Warner, J.H. Controlling Photoluminescence Enhancement and Energy Transfer in $\mathrm{WS}_{2}: \mathrm{hBN}: \mathrm{WS}_{2}$ Vertical Stacks by Precise Interlayer Distances. Small 2020, $16,1905985$. [CrossRef]

10. Zollner, K.; Junior, P.E.F.; Fabian, J. Giant proximity exchange and valley splitting in transition metal dichalcogenide/h-BN/(Co, Ni) heterostructures. Phys. Rev. B 2020, 101, 085112. [CrossRef]

11. Okada, M.; Kutana, A.; Kureishi, Y.; Kobayashi, Y.; Saito, Y.; Saito, T.; Watanabe, K.; Taniguchi, T.; Gupta, S.; Miyata, Y.; et al. Direct and indirect interlayer excitons in a van der Waals heterostructure of hBN/WS $/ \mathrm{MoS}_{2} / \mathrm{Hbn}$. ACS Nano 2018, 12, 2498-2505. [CrossRef]

12. Zhang, F.; Wang, Y.X.; Erb, C.; Wang, K.; Moradifar, P.; Crespi, V.H.; Alem, N. Full orientation control of epitaxial MoS 2 on hBN assisted by substrate defects. Phys. Rev. B 2019, 99, 155430. [CrossRef]

13. Athreya, N.; Leburton, J.P. Electronic Detection of Nucleotides in Multi-Layered MoS 2 -hBN Nanopore FET Devices. Biophys. J. 2020, 118, 157a. [CrossRef]

14. Yosuke, U.; Alex, K.; Watanabe, K.; Taniguchi, T.; Kana, K.; Takahiko, E.; Yasumitsu, M.; Hisanori, S.; Ryo, K. Momentumforbidden dark excitons in hBN-encapsulated monolayer $\mathrm{MoS}_{2}$. NPJ 2D Mater. Appl. 2019, 3. [CrossRef]

15. Wang, Y.; Chen, Y.B.; Wu, X.M.; Zhang, W.Z.; Luo, C.Y.; Li, J.H. Fabrication of $\mathrm{MoS}_{2}$-graphene modified with $\mathrm{Fe}_{3} \mathrm{O}_{4}$ particles and its enhanced microwave absorption performance. Adv. Powder Technol. 2018, 29, 744-750. [CrossRef]

16. Sun, B.; Shi, T.L.; Liu, Z.Y.; Wu, Y.N.; Zhou, J.X.; Liao, G.L. Large-area flexible photodetector based on atomically thin MoS2/graphene film. Mater. Des. 2018, 154,1-7. [CrossRef]

17. Deng, Y.K.; Ding, L.X.; Liu, Q.X.; Zhan, L.; Wang, Y.L.; Yang, S.B. Two-dimensional MoS $_{2}$-graphene hybrid nanosheets for high gravimetric and volumetric lithium storage. Appl. Surf. Sci. 2018, 437, 384-389. [CrossRef]

18. Alamri, M.; Sakidja, R.; Goul, R.; Ghopry, S.; Wu, J.Z. Plasmonic Au nanoparticles on 2D $\mathrm{MoS}_{2} /$ Graphene van der Waals heterostructures for high-sensitivity surface-enhanced Raman spectroscopy. ACS Appl. Nano Mater. 2019, 2, 1412-1420. [CrossRef]

19. Kim, H.U.; Kim, M.; Jin, Y.H.; Hyeon, Y.; Kim, K.S.; An, B.S.; Yang, C.W.; Kanade, V.; Moon, J.Y.; Yeom, G.Y.; et al. Low-temperature wafer-scale growth of $\mathrm{MoS}_{2}$-graphene heterostructures. Appl. Surf. Sci. 2019, 470, 129-134. [CrossRef]

20. Pham, T.; Ramnani, P.; Villarreal, C.C.; Lopez, J.; Das, P.; Lee, I.; Neupane, M.R.; Rheem, Y.; Mulchandani, A. MoS2-graphene heterostructures as efficient organic compounds sensing 2D materials. Carbon 2019, 142, 504-512. [CrossRef]

21. Song, X.Y.; Lu, L.H.; Wei, M.J.; Dai, Z.Y.; Wang, S.S. Molecular dynamics simulations on the water flux in different two-dimension materials. Mol. Simul. 2018, 1-10. [CrossRef]

22. Li, Y.; Ye, F.; Xu, J.; Zhang, W.; Feng, P.X.L.; Zhang, X. Gate-Tuned Temperature in a Hexagonal Boron Nitride-Encapsulated 2-D Semiconductor Device. IEEE Trans. Electron. Devices 2018, 65, 4068-4072. [CrossRef]

23. Calman, E.V.; Fogler, M.M.; Butov, L.V.; Hu, S.; Mishchenko, A.; Geim, A.K. Indirect excitons in van der Waals heterostructures at room temperature. Nat. Commun. 2018, 9, 1-5. [CrossRef] [PubMed]

24. Rhodes, D.; Chae, S.H.; Ribeiro-Palau, R.; Hone, J. Disorder in van der Waals heterostructures of 2D materials. Nat. Mater. 2019, 18, 541. [CrossRef] 
25. Henriques, J.C.G.; Catarina, G.; Costa, A.T.; Fernández-Rossier, J.; Peres, N.M.R. Excitonic magneto-optical Kerr effect in two-dimensional transition metal dichalcogenides induced by spin proximity. Phys. Rev. B 2020, 101, 045408. [CrossRef]

26. Ma, X.Z.; Liu, Q.S.; Xu, D.; Zhu, Y.Z.; Kim, S.G.; Cui, Y.T.; Zhong, L.L.; Liu, M. Capillary-force-assisted clean-stamp transfer of two-dimensional materials. Nano Lett. 2017, 17, 6961-6967. [CrossRef]

27. Christopher, J.W.; Goldberg, B.B.; Swan, A.K. Long tailed trions in monolayer $\mathrm{MoS}_{2}$ : Temperature dependent asymmetry and resulting red-shift of trion photoluminescence spectra. Sci. Rep. 2017, 7, 1-8. [CrossRef]

28. Hu, Y.W.; Zhang, F.; Titze, M.; Deng, B.W.; Li, H.B.; Cheng, G.J. Straining effects in $\mathrm{MoS}_{2}$ monolayer on nanostructured substrates: Temperature-dependent photoluminescence and exciton dynamics. Nanoscale 2018, 10, 5717-5724. [CrossRef]

29. Iqbal, M.Z.; Siddique, S. Ultraviolet-light-driven enhanced hysteresis effect in graphene-tungsten disulfide heterostructures. Carbon 2017, 123, 168-173. [CrossRef]

30. Omar, S.; van Wees, B.J. Graphene-WS ${ }_{2}$ heterostructures for tunable spin injection and spin transport. Phys. Rev. B 2017, 95, 081404. [CrossRef]

31. O'Farrell, E.C.T.; Avsar, A.; Tan, J.Y.; Eda, G.; Ozyilmaz, B. Quantum Transport Detected by Strong Proximity Interaction at a Graphene-WS 2 van der Waals Interface. Nano Lett. 2015, 15, 5682-5688. [CrossRef] [PubMed] 